\title{
RÁDIOS COMUNITÁRAS NA INTERNET: NOVAS POSSIBILIDADES CIDADÃS NO STATUS DAS TECNOLOGIAS ATUAIS
}

\section{Community radio stations on the internet. New ways of exerting citizenship based on current technologies}

\author{
Orlando Maurício de Carvalho BERTI ${ }^{1}$
}

Resumo: Este é um estudo analítico sobre a contemporaneidade brasileira do fenômeno das rádios comunitárias na Internet. Destacam-se suas possibilidades e novidades acerca das tecnologias atuais. Objetiva-se: entender, analisar e refletir esse status, bem como mostrar suas relações e possibilidades cidadãs no atual contexto. Para isso, utiliza-se pesquisa bibliográfica e reflexões balizadas em estudos sobre rádio comunitária e Internet, além de questões de cidadania. Nota-se que a inserção das rádios comunitárias na Rede Mundial de Computadores é um fato crescente de maneira exponencial, mas com subutilizações de seus potenciais agregadores, principalmente voltados à comunidade territorial, que continua sendo o grande objetivo dessas emissoras ao estarem na Internet.

Palavras-chave: Comunicação Social; Comunicação Comunitária; Rádio Comunitária; Cidadania; Internet.

Abstract: This is an analytical study about the present phenomenon, in Brazil, of community radio stations streaming live on the Internet. The study examines the possibilities this process presents and the new technological resources available. The aim of the study is to understand and analyse this phenomenon, as well as to show the role it may play in the lives of the common citizens and the possibilities it currently presents in relation to them. In order to achieve this goal, bibliographical research and practical considerations were used. It is shown that the insertion of the community radio stations on the Internet is increasing exponentially, but that the potential it has to aggregate the community of a given place is still underused, although this is the main reason for these radio stations to be on the Internet.

Keywords: Social Communication; Community Communication; Community Radio Stations; Citizenship; Internet.

\footnotetext{
${ }^{1}$ Doutor em Comunicação Social pela UMESP - Universidade Metodista de São Paulo, Mestre em Comunicação Social pela UMESP, Especialista em Comunicação Institucional pela UFPI - Universidade Federal do Piauí. Possui graduação em Comunicação Social (habilitação em Jornalismo) pela UFPI. É professor Adjunto I, pesquisador e coordenador/executor de projetos de extensão e cursos livres da graduação em Jornalismo da UESPI - Universidade Estadual do Piauí (campus de Teresina e colaboradora do campus de Picos).E-mail: orlandoberti@yahoo.com.br
} 


\section{míDiA

\section{Introdução}

A Comunicação e suas diferentes formas, classificações e estudos passam por constantes transformações. Ousa-se dizer também, adaptando a um termo biológico, que a comunicação sofre mutações. As mesmas são refletidas constantemente em suas sociabilidades e, mais ainda, nas formas de como os seres humanos encaram e vivenciam suas coletividades.

Fala-se que o atual status da comunicação é cada vez mais individual e menos coletivista. Vive-se entremeio ao paradoxo de quanto mais os meios de comunicação nos aproxima mais nos distanciamos do próximo. De que o que está perto termina por estar distante.

Também fala-se em globalidade, em localidade, em glocalidade, em regionalidade, e, claro, no comunitarismo. Pois o comunitário tem força, apesar de também não estar blindado acerca das transformações e dos perigos da contemporaneidade. Entremeio aos fenômenos vigentes, elogiáveis ou polemizáveis, encontram-se as tecnologias atuais: vilãs e/ou mocinhas de parte da potencialização de tantas mudanças.

Utiliza-se o termo tecnologia atual para destacar os conhecimentos ligados à informação e à comunicação na contemporaneidade. São atuais porque destacam o hoje, o agora. Não utiliza-se o termo "novas tecnologias", pois o novo pode ser velho amanhã.

Este estudo tenta ligar o fenômeno das tecnologias atuais a outro caso comunicacional premente e ainda novo em sistematizações acadêmicas: as rádios comunitárias na Internet. Frisa-se que não são as webrádios o sujeito-objeto do estudo, mas sim as rádios na Rede Mundial de Computadores.

É importante destacar o "na comunidade" porque não se levanta uma bandeira do simples estar na Internet, mas sim da retroalimentação que a Rede faz para beneficiar os que estão no ambiente territorial.

Objetiva-se: entender, analisar e refletir esse status, principalmente porque ainda há muitos senões ao fenômeno. Tem-se interesse também de mostrar as relações e 


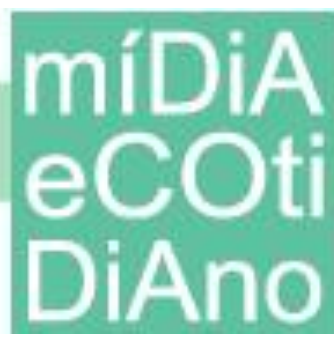

possibilidades cidadãs das emissoras de rádio comunitária no contexto destacado, principalmente em saber as atuais tendências e destacar perspectivas frente ao atual contexto do comunitário na segunda década do Século XXI.

Tem-se como pergunta norteadora: como as rádios comunitárias na Internet trazem novas possibilidades cidadãs junto a suas interlocuções com as tecnologias atuais?

O estudo é justificado academicamente por provocar um fenômeno contemporâneo, bem como sua função científica de tentar desvelar uma problemática atual para abastecer sua mais importante função: a social, que é trazer subsídios para as comunidades que têm (ou pretendem ter) rádios comunitárias e ligá-las com as tecnologias atuais.

Metodologicamente parte-se de um estudo analítico e reflexivo para perspectivas propositivas a fim de cogitar acerca do fenômeno, balizados por pesquisa bibliográfica (com leituras de livros e sítios específicos) e alguns recortes em BERTI (2014) que traz estudos acerca dessa fenomenologia.

O trabalho é dividido em três partes pensadas justamente para realizar uma melhor assimilação e tornar os escritos mais didáticos. A primeira parte: "O que é uma rádio comunitária na Internet?" destaca o fenômeno em si. A segunda "Novas vozes e novas cidadanias. O mutante e dinâmico mundo da Comunicação Comunitária" destaca as emblemáticas possibilidades desse novo comunitarismo. A terceira "Reflexões de novas possibilidades cidadãs das rádios comunitárias na Internet em período de tecnologias atuais" traz a análise do artigo, destacando o que é visto na atual conjuntura acerca do fenômeno.

\section{O que é uma rádio comunitária na Internet?}

Parte-se do conceito básico que uma rádio comunitária é uma emissora da, na e para a comunidade. O conceito é amplo, mas necessário para se dividir uma verdadeira rádio comunitária de uma rádio que usa o termo mas não faz nada a não ser usar os benefícios da lei para praticar coronelismo eletrônico de nova geração, como destacam Venicio Lima e Cristiano Aguiar Lopes (2008). Esse termo denota a captanização dos 


\section{míDiA

espaços das rádios comunitárias no Brasil a favor de grupos político-partidários e religiosos, deixando a comunidade de lado.

Chega a ser ingênuo achar que há uma rádio comunitária perfeita. As emissoras, principalmente pelo atual caráter organizativo dos espaços em que estão representadas, sofrem problemas e muitos apertos, além dos próprios percalços frente a organização social do Século XXI, cada vez mais individual e menos coletiva.

Quando se ressalta que a comunicação comunitária é na comunidade, é trazido um conceito geográfico e de cumplicidade. O próprio espaço comunitário deve ser entendido além do local (bairro ou conglomerados) passando também para um conjunto de comunidades, região de uma cidade ou até um município inteiro.

O "na comunidade" também pode ser o regional (incluindo várias cidades). Mas novamente destaca-se que essa geografia pode ser territorial ou não. Isto porque o conceito de local está mais para pertencimento, que gera participação, do que propriamente dito estar na comunidade totalmente na função territorial. O "na" denota melhor estar dentro, fazer parte.

Por outro lado, quando se fala que a comunicação comunitária é da comunidade, destaca-se uma perspectiva mais participativa no sentido de posse e ação (longe de ser individual e atomizada). É balizada no ter coletivo, entendendo-se participação comunicacional principalmente por meio dos níveis apontados por Cicilia Peruzzo (1998, p.144-145) ao adaptar os conceitos de Jorge Merino Utreras, com a participação ocorrendo de quatro maneiras: (1) através do envio de mensagens representadas por denúncias, entrevistas, pedidos musicais, envio de sugestões; (2) por meio da produção de mensagens, materiais e programas, com aplicação da capacidade pessoal e de qualificação técnica, na produção sistemática ou ocasional de notícias, artigos e outros conteúdos, bem como na preparação, elaboração e edição de materiais comunicativos; (3) no planejamento dos meios, com participação no estabelecimento da política editorial bem como nos princípios de gestão; (4) na gestão dos meios com a participação no processo de administração e controle do veículo ou instituição de comunicação como um todo, sendo que todos esses tipos de participação requerem 


\section{míDiA

existência de canais abertos e desobstruídos. A participação é um ponto-chave para qualquer emissora coletivizante.

Essa "da" também envereda em oportunidades pela caracterização comunitária, como lugar de pertencimento, fatos e atos que instigam participação, principalmente quando a comunidade se acha congraçada e dona dos meios.

E quando se enfatiza que a comunicação comunitária é para a comunidade, é no sentido de sua função, principalmente em serventia para grupos sociais muitas vezes alijados das participações das decisões ou historicamente não incluídos nos meios de comunicação tidos como convencionais, também chamados de comerciais.

O "para" também está ligado à ação do fazer comunicação diferencial, preocupada e proativa à própria comunidade, falando dela, nela e para ela, mas também antenada com o que ocorre a seu redor e atuando em termos da construção da sociedade em geral, incluindo outras comunidades. O "para" promove a incursão de meios próprios de voz.

O grande desafio para a comunidade é continuar com ações comprometidas com a coletividade, principalmente em sua essência de estar em consonância com a comunidade.

O estar na Internet não é apenas a pura e simples utilização das tecnologias atuais para valorizar esse "da", "na" e "para" a comunidade. Em um Brasil de fluxos migratórios, de grandes sociabilidades e de muitas novidades a tecnologia chegou em boa parte das comunidades para ficar, sendo até fruto de estratégias mercadológicas para aumentar público consumidor de mídias.

As rádios comunitárias surgem para garantir a comunitarização desses espaços e também para estarem mais próximas dos novos atores sociais, também conhecidos por "nativos digitais". Esse novo público é, segundo o criador do termo, Mark Prensky (2014), "aqueles que cresceram cercados por tecnologias digitais. Para eles, a tecnologia analógica do século 20 [...] é velha", sendo que os nativos digitais cresceram com a tecnologia digital usando-a com mais propriedade.

Esses nativos continuam interagindo com as emissoras do território, mas, cada vez presentes via tecnologias. A citar, até o final de 2014: dispositivos móveis como smarthphones e tablets. 


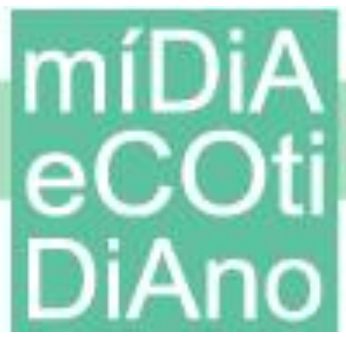

Ao estarem na Internet as emissoras garantem esse público, principalmente para continuarem com suas ações coletivizantes. Não adianta as emissoras ficarem apenas no território físico, tentando apenas se engajar para uma parte da população que, claro, ainda não utiliza das tecnologias atuais. As emissoras devem estar mescladas e adaptadas, mesmo que passem pelos constantes e históricos problemas financeiros. Mas sabe-se que atualmente há diversos sistemas gratuitos que ajudam uma emissora estar na Internet sem tantos custos e até de graça.

\section{Novas vozes e novas cidadanias. $O$ mutante e dinâmico mundo da Comunicação}

\section{Comunitária}

Todo processo comunicacional é dinâmico a partir do momento em que há mudanças em sua forma de emitir ou recepcionar a mensagem. As rádios comunitárias na Internet instigam essas alterações. Por isso a própria Comunicação Comunitária termina também passando por grandes mudanças.

Marcos Palacios (1990, p.104-109) apresenta o que chama de teses equivocadas sobre a Comunicação Comunitária. A primeira é sobre o fato de a consolidação do capitalismo assinalar o fim da ideia de comunidade, sendo que o equívoco reside em a comunidade fortalecer-se, principalmente com o novo simbolismo do que é comunidade, como a comunidade dinâmica.

A segunda é que na sociedade capitalista, dividida em classes antagônicas, a restauração ou instauração da comunidade é uma forma de resistência à lógica capitalista e um instrumento de avanço em direção a formas mais progressistas e humanas de organização social. A crítica é que a evolução comunitária é pautada por pensadores progressistas e não pela própria ação da comunidade em prol disso.

A terceira tese reside no fato de a comunidade ser uma unidade social de tamanho reduzido, que se caracteriza fundamentalmente pela proximidade física entre seus membros e pelos contatos face a face. Essa concepção cai por terra a partir do momento em que se delimita fisicamente a comunidade, principalmente a local, porque a comunidade também faz parte da sociedade, que é muito maior, sendo que ela não é 


\section{míDiA

simplesmente um lugar no mapa, mas também um espaço de experiências, mesmo as pessoas não estejam vivendo obrigatoriamente umas perto das outras.

A quarta tese é a de que a comunicação comunitária se contrapõe à comunicação de massa, e deve se processar por meios alternativos, essencialmente pelos chamados pequenos meios. Ela é equivocada, porque a comunicação comunitária não é só de tamanho reduzido, e essas podem também pautar a grande mídia, e que os meios comunitários também podem ser grandes.

A quinta tese é a de que a comunicação comunitária, na medida em que é feita para a comunidade, deve ser feita por membros da comunidade, excluindo a participação de profissionais. A polêmica reside principalmente na contratação ou não de profissionais. A maioria das emissoras de rádio comunitária realmente não pode contratar, mas algumas têm trabalhos tão profissionais quanto outros meios, principalmente na forma distinta do diferencial no querer fazer melhor.

A sexta tese destaca que a comunicação comunitária deve se estruturar com base nos problemas vivenciados e identificados pela própria comunidade, e não a partir de problemáticas trazidas de fora por elementos externos à comunidade. "Essa é, sem dúvida, uma questão delicada. Quando os problemas são vivenciados e identificados pelos próprios membros da comunidade, é óbvio que existe, de antemão, a movimentação para a participação e o envolvimento" (PALACIOS, 1990, p.108). Coloca-se a questão, portanto, no âmbito da capacidade - maior ou menor - de a equipe, que vai desenvolver um trabalho comunitário, comunicar-se com os membros da comunidade e conscientizá-los da importância da ação a ser empreendida. Não é o fato de uma problemática ser trazida de fora que, automaticamente, a invalida em termos de comunicação comunitária.

A sétima tese destaca que a academia forma profissionais para a comunicação de massa e não para a comunicação comunitária. Esta é uma tese exaustivamente repetida, em diferentes formas, por pessoas ligadas a movimentos de caráter comunitário. Realmente trata-se de uma tese em que a maioria dos estudantes deveria ir a campo, mas uma parte (reconhece-se: ainda minoritária) também vai para os movimentos comunitários. 


\section{míDiA

Em um período histórico também conhecido por "Século do Eu", em que as organicidades são dissipadas e o coletivo muitas vezes é relegado em prol do individualismo ou da competitividade, a comunicação comunitária também cresce, principalmente para suprir esses contrapontos não tão coletivizantes da sociedade. Outro motivo de ascensão e evolução da comunicação comunitária é o desgaste enfrentado pela mídia tradicional, principalmente por, muitas vezes, não dar voz ou não refletir realmente o que ocorre nas comunidades. Essa corrosão também é feita em razão de os meios de comunicação tradicionais muitas vezes alijarem a comunicação comunitária, enveredando apenas por uma perspectiva de dominação e manutenção de um status político e econômico de grupos dominantes ou de grupamentos que pretendem chegar ao poder apenas pelo controle desse poder.

Outro fato é a falta de credibilidade de muitos meios nacionais, comprovadamente simpáticos ao sistema estatal ou a grupos econômicos e político-partidários.

Grandes meios de comunicação brasileiros, apesar de ainda muito poderosos, veem suas audiências e consumidores migrando para outras empresas e para outros meios de comunicação, principalmente porque determinadas fórmulas estão superadas e não mais atingem determinadas parcelas da população.

Mas se no campo de entretenimento tais meios comerciais reinam quase absolutos, no campo da informação (jornalismo), apesar de uma concorrência desleal, os meios comunitários e alternativos atualmente têm um papel de maior credibilidade e penetração, porque boa parte das notícias ocorre nas comunidades e, às vezes, as notícias mais gerais e mais múltiplas não têm grande penetração comunitária por questões de linguagem, identidade, identificação e conquista popular ${ }^{3}$.

\footnotetext{
${ }^{2} \mathrm{O}$ termo Século do Eu é cunhado por causa do documentário homônimo (original The Century of the Self), de Adam Curtis, de 2002, produzido em parceria com a rede BBC, do Reino Unido, que destaca como as teorias de Sigmund Freud foram usadas por seu sobrinho Edward Bernays para manipular massas, dentre outras grandes lições do campo da comunicação massiva em suas contribuições negativas para o Século XX.

${ }^{3}$ É comum que grandes meios de comunicação procurem fazer experimentações em seus conteúdos de ideias comunitárias. O questionamento é se essa transmutação do comunitário para o comercial é benéfico ou apenas mais uma utilização do popular em prol do privado e dos lucros. Em alguns casos dotam-se alguns líderes comunitários, principalmente em lugares de risco de segurança com câmeras, justamente para evitar que profissionais dos meios de comunicação maiores não corram riscos. Isso ocorre em comunidades do Rio de Janeiro e de São Paulo sob a égide de um "jornalismo cidadão". O jornalismo
} 


\section{míDiA

A comunicação comunitária pode ser feita não só por instituições organizadas e movimentos populares, mas também de organizações não governamentais, sindicatos e principalmente grupos interessados na melhoria social dos lugares em que vivem e atuam.

Assinale-se que não é o meio de comunicação utilizado (no sentido de plataforma - sonoro, audiovisual, impresso ou online ou o conjunto deles) que irá caracterizar a comunicação comunitária, mas sim a intencionalidade comunicacional feita $n a$, da e para as comunidades em que esses meios de comunicação pretendem representar, e a sociabilidade de seus processos. Por isso, a comunicação comunitária pode ser feita de maneiras múltiplas, posto que o importante é abranger pessoas, é trabalhar com gente, fazendo acontecer e construir coletivamente um mundo melhor, vivenciando uma utopia prática e sempre se desvencilhar dos perigos do mundo capitalista e suas armadilhas anticomunitaristas ou ainda que não representam nenhum caminho do comunitário.

Um dos grandes desafios da Comunicação Comunitária no século XXI consiste principalmente na manutenção e reconhecimento desses meios, notadamente da própria sociedade em que esses processos comunicacionais são direcionados. Isso é dado principalmente pelo trabalho dos meios e pelo respeito conquistado através de ações de ano, consideração natural de agentes desses meios, geralmente líderes sociais ou pessoas de destaque para uma voz comunicacional, e ainda pelo reconhecimento de ser a única voz que realmente fala e age pela comunidade ${ }^{4}$.

Os conceitos clássicos de cidadania, democracia, política e ideologia, assim como os conceitos de partido político, participação política e poder, voltam a ser questionados na sua validade teórica e na perspectiva da prática e sua capacidade de proporcionar emancipação, justiça social e de criar indivíduos e espaços autônomos que tenham como

cidadão é participativo, mas não é concorrencial e muito menos tira o poder do jornalismo convencional, mas também não pode pôr em risco agentes comunitários justamente por conta da notícia em primeiro momento. Com as dicotomias sociais cada vez maiores no Brasil (incluídos e não incluídos, com poder de alto consumo e os sem tanto poder de consumo, só para exemplificar duas situações), procura-se semihomogeneizar os heterogêneos processos comunicacionais, notadamente das periferias urbanas e comunidades rurais, historicamente alijadas das decisões e da participação direta nos meios de comunicação massivos.

${ }^{4} \mathrm{O}$ poder de voz deve ser compartilhado coletivamente sem personalismos. Quando o meio e sua importância ganham mais destaques que os comunicadores e suas personalidades, a comunicação comunitária envereda por potencializar e ter maior reconhecimento social, inclusive se os mesmos agentes necessitarem de se ausentar ou vivenciar novas missões. 
fim a liberdade e o desenvolvimento das condições históricas de crescimento integral da existência humana (NOGUEIRA; POSSEBOM, 2010, p.3).

Um dos pontos históricos da comunicação comunitária no Brasil foi a realização da Conferência Nacional de Comunicação (Confecom), ocorrida em dezembro de 2009, em Brasília (DF). Esse evento foi um pré-divisor de águas no movimento. Reuniu quase dez mil pessoas oriundas de praticamente todo o País, fruto de uma discussão de mais de quatro meses. Foram aprovadas na Confecom mais de 700 propostas (boa parte delas oriundas dos movimentos sociais e comunitários). Muitos desses aportes versavam diretamente sobre a comunicação comunitária, em especial a radiofônica. Mas até o meio de 2014 quase nenhuma proposta foi posta em lei, mesmo existindo participação estatal (de parte dos ministérios, de agências e de órgãos municipais e estaduais) nos processos de discussão.

A comunicação comunitária brasileira, apesar dos percalços, lutas e reclamações, tem respaldo legal. Ela é regulamentada por duas leis, ambas relativamente novas, conquistadas por meio de muitas polêmicas, após anos de luta. São elas: a Lei número 8.977/95, conhecida também por Lei da TV a cabo, que regulamenta as TVs comunitárias (BRASIL, 2012a) e a Lei número 9.612/98, de Radiodifusão Comunitária, também conhecida por Lei das Rádios Comunitárias, que prevê a regulamentação desses meios de comunicação (BRASIL, 2012b). Essas leis trazem uma série de polêmicas, principalmente pela complicada maneira de se manter uma rádio comunitária, geralmente limitando a forma de se conseguir e manter um canal em nosso País. Por isso o estar na Internet é também um procedimento de garantia das lutas de muitas emissoras enquanto as mesmas não são legalizadas.

\section{Reflexões de novas possibilidades cidadãs das rádios comunitárias na Internet}

\section{em período de tecnologias atuais}

Possibilidades é o que não faltam com a presença das rádios comunitárias na Internet. Em um Brasil dinâmico, o que funciona em uma comunidade não é sinal de sucesso em outra (fatos já provados na comunicação comunitária radiofônica tradicional 


\section{míDiA

- via dial). Mas quando se há coletivização (da mais simples até a mais interativa), incentivo à participação, e os membros da comunidade realmente encaram a emissora como sua (teoria do pertencimento ${ }^{5}$ de Alain Bourdin, 2001): já são sinais de que a emissora fará sucesso, não só de audiência (que deve ser objetivo secundário) mas de integração da própria comunidade. Ao integrar melhores dias podem ser trilhados para a comunidade. Nota-se que mesmo em plena segunda metade do Século XXI "melhores dias" ainda são esperados por décadas por boa parte das comunidades brasileiras.

Deve-se continuar também a não imitar os meios comerciais e público-estatais, esses, em sua grande maioria, com melhores estruturas (de equipamento e de pessoal). É fato que uma emissora com melhor estrutura e com melhor potencial pode plasticamente fazer um melhor trabalho e cativar, ao menos quantitativamente, maior audiência. $\mathrm{O}$ fato é válido não só para emissora territorial, mas também para a emissora na Internet. Por isso o entender e vivenciar a linguagem própria da comunidade e traduzi-la para ferramentas simples é um dos atos que garantirá o sucesso das emissoras comunitárias na Internet.

Nota-se que o movimento de rádios comunitárias do Brasil e sua interface virtual pouco tem se comunicado, pouco tem interagido. Um reflexo das polêmicas e quase infindáveis dissidências entre as organizações que também atuam para defender as emissoras comunitárias no dial.

Há pouca interação até entre as próprias emissoras dos estados e regiões. Uma sugestão, pela gama das tecnologias atuais, seria a criação de redes e portais virtuais que pudessem convergir essas emissoras. Na contemporaneidade quem faz isso é o site Rádios.com ${ }^{6}$ mas de uma maneira geral, englobando as rádios comunitárias ou que se dizem comunitárias em uma seção, contendo seus endereços e informações básicas.

A nova rádio comunitária, desterritorializada pela comunicação via Internet, sai do conceito tradicional, e passa, em vários exemplos e momentos, para um meio global, deixando sua marca apenas de só territorial.

\footnotetext{
${ }^{5} \mathrm{O}$ pertencimento é o ato de estar presente, de interagir com uma comunidade, mesmo o membro não estando fisicamente e interagindo cara a cara com os outros membros.

${ }^{6}$ www.radios.com.br
} 


\section{míDiA

As rádios comunitárias podem até se dar ao luxo de estar apenas no território, objetivo-fim dos processos comunicacionais, mas é um desperdício de potencial o fato de não experimentarem interlocução com a Internet. Em uma geração conectada, principalmente formada por jovens, cada vez mais com acesso aos bancos escolares e ao conhecimento, o pensamento global é premente. Nenhum meio de comunicação, instituição, entidade ou grupo que pensa no futuro deve desprezar a Internet e seu lado positivo (integração e ferramentas para conhecimento, por exemplo). A nova rádio comunitária vivencia a globalidade, mas sempre voltada para o território. Esse globalismo, ao mesmo tempo local nas emissoras de rádio comunitária, principalmente para o caso das sertanejas nordestinas, representa série de virtudes e perigos.

Sabe-se, inclusive, que nem metade das emissoras está on-line e que uma parte das emissoras on-line sequer instigam a participação popular por meio de sites na Internet. Há um grande potencial para mais meios estarem na Rede. Ou seja: não adianta só a emissora ter um espaço na Internet, mas também utilizá-lo e torná-lo dinâmico, isso é o que caracteriza as emissoras online, aquelas que não são só escutadas na Internet, mas também que possibilitam canais de interação e interatividade, principalmente via redes sociais virtuais ou por mecanismos de interligação com o ouvinte, que passa a ser encarado como usuário, um elemento mais participativo no processo comunicacional.

Destaque-se que o interesse, os problemas da alegação de custos financeiros, além da vontade de fazer, pois algumas delas são mantidas por políticos e o que menos querem é estimular a participação, são fatores que mostram que as rádios comunitárias na Internet ainda estão mais para exceção do que para regra, principalmente as participativas.

Mas há a certeza de que as que utilizam mais canais e também as que procuram retroalimentar a comunicação comunitária são as que mais estão preocupadas realmente em interligar a comunicação territorial consigo, bem como os membros da comunidade que estão em outras partes do país.

São virtudes o fato de poderem estar mais presentes nas vidas dos moradores da própria comunidade que agora podem estar em vários pontos e de multiplataformas de acesso virtuais, não mais só no rádio à pilha ou nos aparelhos fixos, mas os ouvintes 


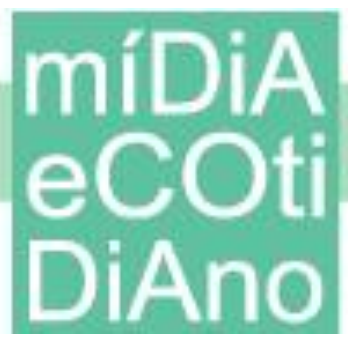

agora podem acompanhar a emissora, em dispositivos móveis, amplamente popularizados e de acesso à maioria da população, mesmo uma parte dela ainda passando fome e tendo fortes dificuldades financeiras.

A integração com o emigrante (aquele que deixa sua terra natal em busca de melhores dias e condições de sobrevivência) também potencializa o trabalho e caracteriza a nova rádio comunitária. Em períodos de estiagem as redes promovidas pelas emissoras na Internet, interligam parentes e fortalecem a comunidade; são exemplos de que as rádios podem muito mais que entreter e só ficar enviando "alôs", mas integrando e potencializando o próprio poder de vivência coletiva.

Ainda que a maioria do que se encontra na literatura sobre a área defenda o território como ponto da comunidade contemporânea, a comunidade virtual deve ser levada em conta, não como um lugar de solidariedade e cumplicidades, como ocorre na territorial, mas como o virtual agregador para o próprio território. Grupos na virtualidade, com discussões, debates e congraçamentos ajudam sim o territorial.

Outro ponto positivo também consiste no fato de a rádio poder ter, inclusive, novos ouvintes, além de seus migrantes propriamente ditos, cativando ouvintes pela Internet de outras cidades, estados e até de outros países.

Também constitui perigo o fato de se achar a tecnologia mais importante do que a comunicação tradicional, além de centrar os esforços apenas nas tecnologias atuais. Os membros das emissoras de rádio comunitária que estão na Internet (e os que pretendem estar) nem podem ser tecnófilos - viciados em tecnologia - e muito menos tecnófobos horrorizados com ela.

Estar atento ao que acontece no Mundo é obrigação de todo comunicador, mas nunca achar que o Facebook, o SMS ou o mundo disponível pelos dispositivos móveis são a chave para o novo comunitarismo. Tais ferramentas são defendidas, mas sempre voltadas para o territorial, pois têm oportunidade de agregar; mas se a agregação não tiver fortalecimento orgânico humano, termina por estar mais que enganado.

A chave continua sendo o cara a cara e a vivência do poder falar, do estar junto, lições que as pequenas cidades e comunidades Brasil adentro ainda dão, principalmente no poder confiar, em sua solidariedade, simplicidade e companheirismo. 


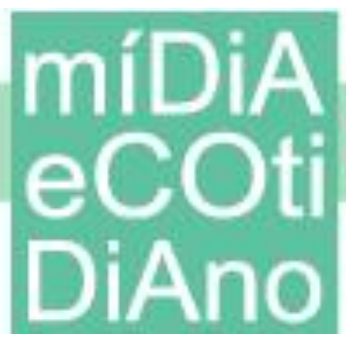

Por mais que os smarthphones já façam parte da vida de muitos brasileiros, a conversa na praça principal da cidade ou na praça pública da comunidade ainda é o principal ponto social. Por mais que haja os vícios tão instigados pelas indústrias culturais, inclusive as regionais e suas músicas, capitaneadas, muitas vezes por uma parte das próprias rádios comunitárias, a cultura tradicional e suas evoluções ainda persistem e fazem parte da vida e da discussão de muitos dos jovens. Essa cultura não pode ser suplantada pelo que vem de fora, mas o que está na comunidade tem de continuar forte e reconhecido, não para se impor ao importado, mas para mostrar também uma identidade própria, que certamente fortalece a própria comunidade, e traz melhores dias coletivos para quem vive nessas regiões e cidades do País, tidas como o fim do mundo, mas que talvez sejam o começo de um novo mundo ou da esperança de que o mundo ainda tem jeito, e a comunicação tem muito a ver com tudo isso.

Nota-se em estudos e sistematizações científicas acerca do fenômeno estudado que há um desejo de várias emissoras, principalmente as com maior interação nos ambientes territoriais que há um desejo de evoluir comunitariamente.

Um fato é que os sites das emissoras de rádio comunitária que estão na Internet precisam ter mais elementos noticiosos e interesse pelo Facebook, principalmente para trazer notícias e debates. Sabe-se que boa parte das rádios comunitárias não conta com equipes especializadas de Jornalismo, mas que a notícia, mesmo na maneira simples de ser dessas rádios, deve ser uma constante. Um ponto é que os comunicadores dessas emissoras possam ser formados para o encarar noticioso ${ }^{7}$.

Entender a concorrência com o Facebook e o envolver os jovens são os principais pontos consonantes para muitas outras emissoras. Bem como entender o programa de mensagem instantânea Whatsapp é outro ponto, pois ele promove uma dinamicidade de participação e vivencia virtual, também envolvendo muito os jovens.

\footnotetext{
${ }^{7}$ Uma sugestão é para que as universidades (via cursos de curta duração, cursos de extensão e até cursos de Pós-graduação Lato Sensu - Especialização) e entidades da sociedade civil organizada, principalmente aquelas que militam com comunicação e cidadania, possam comprar e pôr em prática essas ideias.
} 


\section{míDiA

Outro desafio é a manutenção financeira, já que transborda a força de vontade de várias emissoras estarem na Internet, mas, por problemas financeiros, pouco podem pagar. Uma solução é a utilização de sistemas gratuitos.

Nota-se que em várias emissoras mais antigas o desafio é voltar a fortalecer as redes sociais virtuais, já que a sua popularização de várias dessas rádios é bem reconhecida por suas atividades culturais locais.

A desterritorialização é bem-vinda, as novas rádios comunitárias estão desafiadas, cabe ao ser humano mudar, interatuar e vivenciar novos dias. É assim que se constrói uma nova e diferente sociedade, pelo menos mais interconectada e com mais canais para um mundo melhor e, consequentemente, mais cidadão.

\section{Considerações finais}

As rádios comunitárias online são as que têm conteúdo agregador por causa de sua transmissão e canais extras de participação, além do que é trazido no dial, potencializam o comunitário e mesmo a Internet, que antes era tida como meio desagregador da comunidade, por, teoricamente, desarticular o local. Por mundializar suas sociabilidades, ela é tida, ao menos no fenômeno estudado, como agregadora e retroalimentadora, pois a Rede, símbolo da globalização, não é fim dos processos comunicacionais comunitários, mas ajuda na mediação e integração entre os sujeitos desse processo, mesmo entre os que não estão no território físico, originalmente acolhedor da emissora de rádio comunitária.

Elas levam em conta suas atuações como emissora convencional no dial e no ciberespaço, e estão cientes do potencial de beneficiar os ouvintes (que estão no território) e o novo público gerado pelas transmissões na Internet, gerando a recepção dos usuários. Há mais noção ainda de que os dois públicos podem ser um só, mesmo os segundos não estando presencialmente no território das transmissões no dial.

A retroalimentação atua na individualidade do receptor, a partir do momento em que mata a saudade de um parente, de um amigo, de uma música que há tempo não escutava, pois nas grandes cidades não há tanta identificação com o que se escuta no rádio, além de saber o que acontece entre seus pares e ainda poder participar, mesmo 


\section{míDiA

remotamente, das decisões e cobranças por melhorias no seu local de nascimento e educação. Mas também a retroalimentação age na coletividade, aproxima públicos, age em campanhas, não só entre membros da comunidade que estão distantes, mas também entre as zonas urbanas e rurais, já que muitas comunidades rurais são distantes (e, nos casos estudados, geralmente as zonas rurais têm mais habitantes que as zonas urbanas).

Nota-se que boa parte dessas emissoras, até pela carência de meios de comunicação locais e regionais compromissados com as causas sociais e de cidadania, terminam transcendendo o papel de rádios comunitárias, e passam para uma função mais abrangente. Além de entreter, noticiar, tentar formar para atitudes cidadãs na própria comunidade, acabam sendo meio de proporções geográficas maiores. Há forte inclinação para as emissoras assumirem para si o papel de promotoras da cidadania, fato constatado acerca de suas reais intenções para com a participação dos ouvintes e dos usuários.

Ao estar na Internet, essas emissoras têm seu trabalho e suas ações mais potencializadas, principalmente, por estimular a participação, interação, interatividade e cidadania.

Esses destaques são necessários para entender o novo comunitarismo radiofônico, e, consequentemente, o territorial, promovido também pela desterritorialização da Comunicação Comunitária Radiofônica incentivada pela Internet. A retroalimentação da comunicação tradicional, em ambiente territorial, traz frutos que mundializam as emissoras e integram o emigrante com a comunidade originária, além de dar mais espaço para as causas sociais, econômicas e políticas, além da integração natural daqueles que ficam com os que estão longe de sua cidade natal.

O lugar isolado de outrora evolui e não mais é apenas o do cara a cara, mas o espaço de interrelações entre os moradores e seus antigos membros que necessitaram emigrar. As distâncias, antes de milhares de quilômetros e dirimidas por telefonemas semanais, mensais ou até pela distância e tempo do envio de correspondências, agora são diminuídas diariamente pela utilização de SMS enviados para as emissoras, ou ainda a utilização de seus espaços virtuais. 


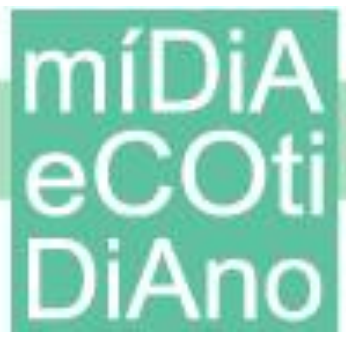

PPGMC

A participação também é destacada a partir do aumento de canais em interlocução com as redes sociais virtuais. Participar não significa só enviar alô, mas também estar consonante com o que está ao redor ou então circundante em relação aos membros da comunidade territorial. A participação virtual tem como objetivo-fim a melhoria das condições de vida no território geográfico. Conclui-se, portanto, que a participação nas rádios comunitárias sertanejas nordestinas também desterritorializa e retroalimenta a comunicação comunitária.

A interação também é destacada porque, com o uso das ferramentas virtuais nos sites das emissoras, há mais espaços sociais, e a própria comunidade ganha social, econômica e politicamente, além de ter mais elementos para a luta e sua evolução.

Nota-se, como pontos válidos para uma reflexão acerca do trabalho dessas emissoras, maior presença da Academia (tanto em seus trabalhos de graduação quanto de Pós-Graduação) em entender melhor as temáticas, principalmente, as ligadas à comunicação Comunitária, Local e Regional, temáticas muitas vezes suplantadas até em Programas de Pós-Graduação Stricto Sensu nitidamente autorizados a pensar as regiões e suas interfaces comunicacionais.

\section{Referências bibliográficas}

BERTI, Orlando Maurício de Carvalho. Processos comunicacionais nas rádios comunitárias do Sertão do Nordeste brasileiro na Internet. São Bernardo do Campo: Tese apresentado ao Programa de Pós-graduação em Comunicação Social da Universidade Metodista de São Paulo, 2014.

BOURDIN, Alain. A questão local. Rio de Janeiro: DP\&A, 2001.

BRASIL. Lei n. 8.977, de 06 de janeiro de 1995. Disponível em: <http://www.planalto.gov.br/ccivil_03/leis/L8977.htm>. Acesso em: 12 nov.2012a.

Lei n. 9.612, de 19 de fevereiro de 1998. Disponível em: <http://www.planalto.gov.br/ccivil_03/leis/L9612.htm>. Acesso em: 12 nov.2012b.

LIMA, Venício A. de. LOPES; Cristiano Aguiar. Rádios comunitárias: coronelismo eletrônico de novo tipo (1999-2004). In: ROLIM, Renata (Org.). Rádio, movimentos sociais e direito à comunicação. Recife: Oito de Março, 2008. 
NOGUEIRA, Silas; POSSEBON, Alessandra. Comunicação e cidadania: diálogo necessário. Caxias do Sul. Anais do XXXIII Congresso Brasileiro de Ciências da Comunicação, 2010.

PALACIOS, Marcos. Sete teses equivocadas sobre comunidade e comunicação comunitária. Revista Comunicação \& Política. Salvador, v. 9, n.11, p.103-110. abr./jun. 1990.

PERUZZO, Cicilia Maria Krohling. Comunicação nos movimentos populares - a participação na construção da cidadania. Petrópolis: Vozes, 1998.

PRENSKY, Marc. Nativos digitais e imigrantes digitais. Disponível em: $<$ http://m.folha.uol.com.br/saber/983798-leia-entrevista-do-autor-da-expressaoimigrantes-digitais.html>. Acesso em: 13 dez.2014. 